\title{
Barriers to asymptomatic screening and other STD services for adolescents and young adults: focus group discussions Elizabeth C Tilson*1, Victoria Sanchez ${ }^{1}$, Chandra L Ford ${ }^{1}$, Marlene Smurzynski ${ }^{1}$, Peter A Leone ${ }^{2,3}$, Kimberley K Fox ${ }^{4,5}$, Kathleen Irwin and William C Miller ${ }^{1,2}$
}

\author{
Address: ${ }^{1}$ University of North Carolina School of Public Health, Rosenau Hall, Chapel Hill, NC, 27599, USA, ${ }^{2}$ University of North Carolina School \\ of Medicine, Manning Dr, Chapel Hill, NC, 27599, USA, ${ }^{3}$ Wake County Human Services-Public Health Center, 10 Sunnybrook Rd, Raleigh, NC, \\ 27620-4049, USA, ${ }^{4}$ North Carolina Department of Health and Human Services, Division of Public Health, Raleigh, NC 27699-1915, USA and \\ ${ }^{5}$ Centers for Disease Control and Prevention, Division of STD Prevention, 1600 Clifton Rd., Atlanta, GA 30333, USA \\ Email: Elizabeth C Tilson* - elizabeth.tilson@co.wake.nc.us; Victoria Sanchez - vsanchez@email.unc.edu; \\ Chandra L Ford - clford@email.unc.edu; Marlene Smurzynski - msmurzyn@email.unc.edu; Peter A Leone - pal007@med.unc.edu; \\ Kimberley K Fox - kaf6@cdc.gov; Kathleen Irwin - kli1@cdc.gov; William C Miller - Bill_Miller@unc.edu \\ * Corresponding author
}

Published: 09 June 2004

BMC Public Health 2004, 4:21
Received: 28 April 2004

Accepted: 09 June 2004

This article is available from: http://www.biomedcentral.com/I47I-2458/4/2I

(C) 2004 Tilson et al; licensee BioMed Central Ltd. This is an Open Access article: verbatim copying and redistribution of this article are permitted in all media for any purpose, provided this notice is preserved along with the article's original URL.

\begin{abstract}
Background: Sexually transmitted diseases (STDs) are a major public health problem among young people and can lead to the spread of HIV. Previous studies have primarily addressed barriers to STD care for symptomatic patients. The purpose of our study was to identify perceptions about existing barriers to and ideal services for STDs, especially asymptomatic screening, among young people in a southeastern community.
\end{abstract}

Methods: Eight focus group discussions including 53 White, African American, and Latino youth (age 14-24) were conducted.

Results: Perceived barriers to care included lack of knowledge of STDs and available services, cost, shame associated with seeking services, long clinic waiting times, discrimination, and urethral specimen collection methods. Perceived features of ideal STD services included locations close to familiar places, extended hours, and urine-based screening. Television was perceived as the most effective route of disseminating STD information.

Conclusions: Further research is warranted to evaluate improving convenience, efficiency, and privacy of existing services; adding urine-based screening and new services closer to neighborhoods; and using mass media to disseminate STD information as strategies to increase STD screening.

\section{Background}

Sexually transmitted diseases (STDs) are a major public health problem among adolescents and young adults. More than fifteen million new cases of STDs are diagnosed every year and approximately $65 \%$ of these cases are diagnosed in people under the age of 24 years. [1,2] STDs contribute to pelvic inflammatory disease, infertility, ectopic pregnancy, premature births, and anogenital cancer and may contribute to the spread of the HIV epidemic. $[2,3]$ The estimated annual cost of major STDs in 
the United States is $\$ 10$ billion, or if sexually transmitted HIV infections are included, $\$ 17$ billion. [2]

Secondary prevention efforts, aimed at interrupting disease transmission, are dependent upon identifying and lessening barriers to accessible STD services. $[4,5]$ Recognized barriers to STD services include system level barriers, such as long waiting times, cost, and inconvenient clinic hours; [6] societal barriers, such as fear and stigma attached to STDs; $[1,7,8]$ and interpersonal barriers, such as judgmental and discriminatory behavior on the part of staff and providers. $[9,10]$ Young people may experience more barriers to STD services than their older counterparts due to limited resources, lack of information, and increased sensitivity to others' perceptions of themselves. $[1,7,11]$

Prior research examining barriers to STD services has been performed primarily in STD clinics with symptomatic patients and exposed partners. [6,8,12,13] However, a high proportion of STD cases are asymptomatic; for example, as many as $85 \%$ of women with chlamydial infection are asymptomatic. $[2,14]$ Barriers to STD care must be evaluated in a population broader than that choosing to attend STD clinics, including those who may seek asymptomatic screening. Furthermore, as knowledge, attitudes, sexual practices, exposure to STDs, and health care seeking behavior may differ among ethnic groups, [3,15-17] information gathered for the purpose of improving services for a broader population must include a diverse sample of participants.

As an initial step towards learning more about barriers to and improving care for both symptomatic and asymptomatic STDs in a North Carolina community, we conducted focus group discussions with youth recruited from non-medical settings in Wake County, NC.

The focus group discussions addressed perceived barriers to accessing STD services, including screening, for adolescents and young adults and perceived ideal characteristics of STD services for this population.

\section{Methods \\ Study setting}

The study was conducted in Wake County, North Carolina, an area with an estimated population of 627,846 in 2000. Approximately $72 \%$ of Wake County residents are White, 20\% are African American, and 5\% are Latino and $75 \%$ are less than 45 years old. [18] In 2000, among all the states, North Carolina ranked second in the number of primary and secondary syphilis cases, ninth in gonorrhea cases, and tenth in cases of chlamydial infection. [19] In 2000, Wake County ranked fifth among the 100 counties in the state of North Carolina in primary and secondary syphilis cases, third in gonorrhea cases, and fifth in cases of chlamydial infection. [20] Rates of STDs were higher among adolescents, young adults, minority populations, and populations with low socioeconomic status as compared to other populations within Wake County. [20]

STD services available in Wake County include the Wake County Human Services Public Health Center which offers free STD screening, testing and treatment in a specialized STD clinic. Several smaller private, not-for-profit clinical sites provide STD services on a sliding fee scale. Three community private, not-for-profit medical centers, several university health clinics, and many private physician practices also provide diagnostic STD testing for persons presenting with symptoms of STDs. The majority of these sites, however, do not routinely provide STD screening of asymptomatic persons.

\section{Focus groups}

Fifty-three young people, aged 14 to 24 years, participated in 8 focus group discussions in the spring and summer of 2000 using methods approved by the Institutional Review Boards of the University of North Carolina, the North Carolina Department of Health and Human Services, and the Centers for Disease Control and Prevention. Groups were composed of males recruited from a juvenile detention center as well as White, African American, and Latino males and females recruited directly from the community (Table 1). Participants were grouped by ethnicity and gender to promote participant comfort.

Table I: Characteristics of participants of eight focus groups that assessed barriers to STD screening and testing $(\mathrm{N}=53)$

\begin{tabular}{lll}
\hline Group & Composition & Median Age in years (range) \\
\hline 1 & 5 African American males & $23(17-24)$ \\
2 & 6 African American males & $17(16-24)$ \\
3 & 7 African American females & $18(16-23)$ \\
4 & 8 Latino males & $21(19-24)$ \\
5 & 5 Latina females & $22(20-23)$ \\
6 & 8 White males & $16(16-19)$ \\
7 & 4 White females & $16(15-16)$ \\
8 & Ethnically mixed group of 10 males in a juvenile & $15(14-16)$ \\
& detention center &
\end{tabular}


Participants were recruited using convenience sampling methods based on age and ethnicity. Youth of the target age and ethnicity were invited to participate in a focus group discussion through face-to-face and phone contact with health education and outreach workers of the Wake County Human Services HIV/STD program, the Wake County Human Services Syphilis Elimination Project team, and one of the investigators (ECT). The juvenile detention center group was conducted on-site with youth in one of the facility's units after receiving permission from the Center's director and state-level administrators.

Five focus group moderators, trained in one-on-one sessions, were matched to participants on gender and ethnicity whenever possible (five of the eight groups) to promote participant comfort. The moderators used a 23item semi-structured discussion guide that was developed to address the following topics: 1) participants' knowledge of STDs including modes of transmission, symptoms of diseases, and possibility of asymptomatic disease; 2) participants' knowledge of existing STD services in the community; 3 ) barriers to STD services perceived or experienced by participants including logistical barriers (e.g. cost, transportation, clinic hours) and personal barriers (e.g. shame associated with seeking STD care, concern of confidentiality, fear of judgmental provider attitudes); 4) participants' suggestions about ideal characteristics of STD services within and outside of traditional clinical settings ; and 5) sources of and suggestions for methods to disseminate STD related information to youth. The final version of the guide was developed based on a pilot test group. Questions were posed in an open-ended manner followed by more specific prompts. The script was translated into Spanish for the Latino groups and then back translated into English for verification. Participants were asked to report their age at the start of the discussion.

The discussions lasted approximately 1.5 hours. Participants received fifteen dollars and refreshments. To promote confidentiality, participants were identified by first name only and provided verbal consent. The discussions were audiotaped and then transcribed verbatim by a transcriptionist who was not involved in data collection or analysis. With the aid of Ethnograph qualitative software (Qualis Research Associates, Salt Lake City, UT), a content analysis of the transcripts was done by an analyst independent of the data collection to generate concepts and identify key themes and patterns. An initial list of codes, corresponding to the question categories in the focus group discussion guide, was developed and additional codes were created by the analyst as themes emerged from the data. One of the authors (ECT) compared the results to the original transcripts to ascertain if the coding scheme and analysis accurately represented the discussions.

\section{Results}

The median age of the participants was 18 (range 14-24) (Table 1). The White participants and the multiracial group from the juvenile detention center were younger than the other participants.

\section{Knowledge of STDs, including asymptomatic disease, and STD services}

Knowledge of STDs, including the possibility of asymptomatic disease other than HIV, was high among the African American females, but generally low among the other groups. In addition, participants expressed a lack of awareness of the importance of screening to detect asymptomatic STDs. For example, one participant stated: "Yes, I am surprised since I may have... any of us can have [STDs] and not know it...since [we] don't know, we don't go to the doctor's...." and another questioned: "What would the problem be with having something that doesn't ever show itself?" (Table 2).

Overall knowledge of available STD testing locations in Wake County was also limited. Very few participants knew of the smaller, private, not-for-profit testing locations. When asked where they would go for STD screening and other care, participants' responses varied by ethnic group. African American and Latino participants most frequently named the county health department or the public nonprofit medical center located next to the health department as a site for STD testing. The White male participants were more likely to mention private doctors. Most White female participants admitted that they "would have no idea where to go" to seek STD services.

Participants reported that they had mostly learned about STDs and available services from friends or "the street" and acknowledged that the information was not necessarily reliable. Participants reported that information gained from health care providers or health education outreach was trusted but limited. In addition, participants reported receiving little information from their parents and stated that, "You don't discuss this stuff with your parents." Finally, participants also reported that they had not learned much about STDs in Wake County schools beyond "the basics" because "they aren't supposed to teach it."

\section{Barriers to testing and screening}

Participants were receptive to the idea of routine annual screening for asymptomatic STDs if they were sexually active. However, several key barriers to seeking care, in addition to limited knowledge of both STDs and available services, were identified.

Participants from all groups reported that out-of-pocket cost was a significant barrier to receiving care and that 
Table 2: Themes and illustrative quotes from eight focus groups demonstrating perceived barriers to STD case

\begin{tabular}{|c|c|}
\hline Theme & Illustrative Quotes \\
\hline Lack of STD knowledge among youth & "[although we are able to name STDs], we don't know what any of these are." \\
\hline \multirow[t]{2}{*}{ Prohibitive cost of STD services } & $\begin{array}{l}\text { "Sometimes people put up with something for that reason [the cost]. We say 'No, because afterwards } \\
\text { there will be bills." }\end{array}$ \\
\hline & $\begin{array}{l}\text { "I wouldn't have any idea about like paying the bill. I don't pay bills. I don't have a job right now. I don't } \\
\text { have a credit card." }\end{array}$ \\
\hline \multirow[t]{2}{*}{$\begin{array}{l}\text { Lack of privacy when seeking STD } \\
\text { services }\end{array}$} & $\begin{array}{l}\text { "...you [have] to go to a special side of the building, like Clinic A or something, and everybody know } \\
\text { you're going in there because you got a [STD]." }\end{array}$ \\
\hline & "that's why when people wait in the waiting room, they be like 'I hope don't nobody come and see me!"' \\
\hline Lengthy waits at STD service sites & $\begin{array}{l}\text { "...Say if you go to a private doctor, you know what I'm saying, it won't even take you - you just go in } \\
\text { there, boom, get your physical and you're gone. But you come here [health department], you got to wait, } \\
\text { wait, wait." }\end{array}$ \\
\hline Language barrier at STD service sites & $\begin{array}{l}\text { "...They give you your form and you fill it out. Then they tell you to go sit down and then you're there for } \\
\text { a long time, you spend almost the whole day sitting there waiting while they try to find a translator." }\end{array}$ \\
\hline \multirow[t]{2}{*}{ Perceived discrimination at clinical sites } & $\begin{array}{l}\text { "Several Mexicans went [to the hospital] dying and in pain...And they wouldn't take care of us...Why } \\
\text { weren't the Mexicans being treated like the Americans? Because of insurance, because of money." }\end{array}$ \\
\hline & $\begin{array}{l}\text { "There are a lot of racist [doctors] who don't like Mexicans, they treat the Americans, they treat the } \\
\text { blacks, but us, they give us the evil eye." }\end{array}$ \\
\hline $\begin{array}{l}\text { Perceived judgmental or punitive STD } \\
\text { providers }\end{array}$ & $\begin{array}{l}\text { [hearing about punitive providers would] "just make it a completely different environment - just knowing } \\
\text { that...would make me not want to go." }\end{array}$ \\
\hline Urethral swabs not acceptable & $\begin{array}{l}\text { "Well, if you're scared about it, yeah. Like, if you heard that somebody that you'd been involved with has } \\
\text { an STD, or if you're having symptoms, of course you're gonna get tested, but if it's just regular, man, } \\
\text { there's no reason to make it [a swab]. That's the worst solution...that's why nobody gets tested." }\end{array}$ \\
\hline
\end{tabular}

"For a young person, ...the first thing one would ask is how much it is going to cost." Participants stressed that free or low-cost services would facilitate seeking care (Table 2). In addition, the White males reported that the fear of a bill for STD services being sent to their parents might serve as an added deterrent to seeking services.

Although free services were viewed as an advantage of the health department, the lack of privacy was noted to be a significant disadvantage. Participants across groups expressed concern and a feeling of shame about being witnessed visiting the health department STD clinic. (Table 2) However, participants described this barrier to be more salient for seeking asymptomatic care and reported if they were "burning" they "wouldn't even care" who saw them go to a clinic. In addition, participants expressed worry about whether STD test results from the health department would remain confidential, and reported that private doctors were more likely to ensure that "your business don't get out."

Participants who had accessed services in public health settings described frustrations with lengthy waits for care (Table 2). Latino participants noted that delays were linked to the scarcity of Spanish speaking interpreters in health care settings. Some Latino men also attributed health care delays to discrimination against Mexicans and the perception that they would be unable to pay, although this perception was not uniform among these partici- pants. Some Latino males described other episodes of perceived racism on the part of health care providers; however, none of the White, African American, and Latina participants noted any similar episodes or perceptions (Table 2).

None of the participants reported having directly experienced or heard of instances in which providers delivering STD care were punitive or judgmental. However, African American and White female participants perceived these negative provider attitudes as a potential barrier to seeking screening or testing. (Table 2) For example one participant stated that "...A lot of people are ashamed [about STDs] anyway... if you feel like people are looking down on you and you hear 'em talking and they're staring at you...you know, just making little smart comments, then you don't want to go!"

Almost all male participants expressed a strong aversion to urethral swabs as a specimen collection modality. Again, participants described urethral swabs as a greater barrier to asymptomatic screening than testing due symptoms or a known exposure to an infected partner (Table 2).

\section{Perceived ideal characteristics of STD services for adolescents and young adults}

Participants in all eight groups consistently voiced several strong preferences (Table 3 ), stating that the ideal clinic 
Table 3: Themes and illustrative quotes about desired features of ideal STD services from eight focus groups

\begin{tabular}{|c|c|}
\hline Desired feature & Illustrative Quotes \\
\hline \multicolumn{2}{|l|}{ Features consistent across groups } \\
\hline Familiar and frequented location & $\begin{array}{l}\text { "It should be near home...and just not out in the middle of nowhere, so it's not like you're doing } \\
\text { something illegal and you've got to drive miles in the car...and make it easier too, just to like stop by } \\
\text { before you go to the mall." }\end{array}$ \\
\hline Professional but welcoming & "It would be nice to be kind of a relaxed atmosphere, yet professional." \\
\hline Open evening and weekend hours & $\begin{array}{l}\text { "From } 5 \text { to } 8 \text { p.m. Because, many... All the Mexicans work. Thanks to God, from six a.m. to five p.m for } \\
\text { those who work in construction...There should be two shifts: one in the morning and another in the } \\
\text { evening..." } \\
\text { "I have class till 5:30 and that means I can't do anything with my Wednesdays since everything closes at } 5 . "\end{array}$ \\
\hline Urine-based STD screening offered & "But l'd be much more tempted if it was just a pee in a cup thing." \\
\hline $\begin{array}{l}\text { Counseling and health education } \\
\text { offered }\end{array}$ & $\begin{array}{l}\text { "Some teenagers are scared to talk to their parents about what they're doing, so I think [it would be good] } \\
\text { if you have someone that you can talk to." }\end{array}$ \\
\hline \multicolumn{2}{|l|}{ Features inconsistent across groups } \\
\hline \multirow[t]{2}{*}{$\begin{array}{l}\text { Offering non-STD services with STD } \\
\text { services }\end{array}$} & $\begin{array}{l}\text { "...There are some who won't go, out of embarrassment...If they saw that people were going to the clinic } \\
\text { for all sorts of diseases, well then...they would no longer have a reason to be embarrassed, because no } \\
\text { one would know." }\end{array}$ \\
\hline & $\begin{array}{l}\text { "You wouldn't feel so alone if the clinic was specialized in that, you know, you'd feel like, 'I'm not the only } \\
\text { one' ...." }\end{array}$ \\
\hline \multirow[t]{2}{*}{$\begin{array}{l}\text { Offering screening in non-clinical } \\
\text { community sites }\end{array}$} & $\begin{array}{l}\text { "If I was faced with an STD, I wouldn't want it to be such a big ordeal...and if it was at some place like the } \\
\text { "Y" that I go a lot and feel comfortable there, then it would probably make it less scary than if I just went } \\
\text { to this huge health service place and it was just like totally out of my comfort zone." }\end{array}$ \\
\hline & $\begin{array}{l}\text { "I would not feel comfortable going to such a public place as the mall or something like that. ...It would be } \\
\text { like, 'Well, if I go to the mall, I hope I don't see my friends like I do every time I go to the mall!"' }\end{array}$ \\
\hline
\end{tabular}

should be "close to where we live," welcoming, confidential, efficient, and welcoming. As one participant stated, "..you're obviously not going to go there with an adult and...you need something that's really comfortable for a 16 , or however old, kid to go in and know what to do and not feel lost." In addition, participants reported that evening and weekend hours of operation would be important as "For our generation, being 18 to 24 , then 5:00 just doesn't really cut it." Males stressed the need for urine-based screening and female participants expressed wishes for health education and counseling services at the time of screening or testing (Table 3 ) as exemplified by the following statement: "I think it is also very important that they offer psychological treatment and social work, because....I think I would be worried and scared...."

Participants reported that the ideal clinic should offer and advertise a broad package of health services including STD services to decrease the embarrassment associated with being witnessed accessing services. However, a few participants suggested they may feel more comfortable in a clinic dedicated to STD care, as it would reduce the embarrassment associated with telling the staff the reason for their visit. (Table 3).

Most of the participants, except for the African American males, reported that they would be more comfortable with a provider of the same gender as themselves. Almost all of the participants reported that the racial/ethnic back- ground of the provider would be unimportant for their comfort, as long as the provider "knows what they are doing," is respectful, and is someone with whom they can communicate. However, a few Latino participants expressed a preference for a Mexican provider, as they "believe [d] that a Mexican is not going to be mean with his own people."

Participants' reactions to screening for STDs at a non-clinical community site were mixed. Some participants reported that screening services available in a non-clinical setting frequented by young people (e.g. recreational center, community center) would be acceptable and may prompt more youth to be screened. Others, however, expressed concern that some non-medical locations, for example the mall, would be too public to ensure privacy (Table 3).

Participants reported that the broad reach and subliminal nature of advertising on television or radio would make those media the most effective avenue for disseminating information on STDs and available services to youth (Table 4). As the participants note, "people watch television everyday."

Participants also proposed that STD information could be provided through the junior and senior high schools, noting that schools are a setting in which most youth could be contacted. As one participant stated: "[STD informa- 
Table 4: Themes about potential communication methods for STD information

\begin{tabular}{|c|c|}
\hline Theme & Illustrative Quote \\
\hline \multirow[t]{2}{*}{$\begin{array}{l}\text { Disseminate STD information through } \\
\text { television and radio }\end{array}$} & $\begin{array}{l}\text { "[commercials have subliminal effects since] you could be looking at TV and not really paying attention to } \\
\text { it, but it be in your subconscience." }\end{array}$ \\
\hline & $\begin{array}{l}\text { "There should be some commercials that have a whole lot of pretty people saying, 'I bet you didn't know I } \\
\text { had an STD."' }\end{array}$ \\
\hline Provide STD information in schools & $\begin{array}{l}\text { "All these kids...are just sitting there, waiting for you to throw stuff at them. You have their attention in } \\
\text { health class. They could take advantage of that." }\end{array}$ \\
\hline \multirow[t]{2}{*}{$\begin{array}{l}\text { Provide information through } \\
\text { community outreach activities }\end{array}$} & $\begin{array}{l}\text { "Go to every project and do like y'all are doing now. Get some tables and sit up on the corner and [give } \\
\text { people information]." }\end{array}$ \\
\hline & $\begin{array}{l}\text { "I know. Put some adolescents on your payroll. Give them about } \$ 15 \text { and tell them to go tell others } \\
\text { [about STDs]. That would get the job done." }\end{array}$ \\
\hline \multirow[t]{2}{*}{$\begin{array}{l}\text { Provide STD information on the } \\
\text { internet }\end{array}$} & $\begin{array}{l}\text { "I think if you can't it through the school, I think the internet is the next step down. Because everyone is } \\
\text { on the internet." }\end{array}$ \\
\hline & $\begin{array}{l}\text { "You need an accessible home page [with an address like] 'STD' ...or something like that and that way you } \\
\text { don't have to memorize anything. If you ever come across a problem, you just type that in and you're at } \\
\text { the place. }\end{array}$ \\
\hline
\end{tabular}

tion] definitely should be in school, though, because that's the common denominator that everybody has. Whether you're in a city or a small town." In addition, participants suggested STD information could be provided through community outreach activities and the Internet (Table 4).

\section{Discussion}

Many barriers identified by other studies, including a lack of knowledge of STDs and available services, cost of services, long waiting times, conflicts between clinic hours and work and school schedules, embarrassment attached to seeking STD services, and method of specimen collection were also identified by our diverse sample of Wake County youth. $[1,11,13]$ This suggests that these barriers may be fairly universal among different populations. Participants also suggested that these barriers may more effectively deter youth from seeking asymptomatic screening as compared to seeking testing due to symptomatic disease or a known exposure.

Conversely, with the exception of some Latino males, interpersonal barriers with health care providers identified by other studies, including scolding and stigmatizing of patients by staff [10] and racial discrimination, $[13,21]$ were not reported as potential or actual barriers by our participants. In addition, provider ethnicity also seemed unimportant to most of the participants as long as the provider could deliver effective, competent care.

Several opportunities for improving STD care in Wake County were identified by our participants. Although increasing public knowledge of STDs among youth, including the possibility of asymptomatic disease and available services, may not be sufficient to increase screening and testing, it may be a necessary first step as many of our participants expressed a lack of basic STD knowledge or sources of information. Our participants, as well as adults in other studies, have identified television and radio as an acceptable source of sexuality information. [22] These media already represents a leading source of sexuality information for adolescents and television has been effective in promoting the use of family-planning clinics in some American communities. $[23,24]$ The use of these media for STD public health campaigns may warrant further evaluation through additional research.

Increasing STD information in schools in Wake County may also be warranted. Our participants noted the advantages of providing information in locations regularly attended by youth. In addition, school-based sexuality education curriculums, including discussion of both abstinence and contraception, have been shown to promote STD-protective behavior. [25] Finally, attempts to improve parent-adolescent communication about STDs may also be needed. Our participants reported an almost universally low level of parent-adolescent communication about STDs, yet open, skilled communication between parents and children has been shown to promote STD-protective behavior. $[3,26,27]$

Participants also described ideal features of STD services. Many of the ideal service features cited, including convenience, a welcoming atmosphere, confidentiality, efficiency, and low-cost, characterize some of the smaller private, not-for-profit clinical locations in Wake County with which few participants were familiar. Raising awareness of these existing services among Wake County's youth might be an initial strategy for increasing access to STD care. Modifying existing services at the public health settings that were more widely known by participants by extending hours of operations, redesigning waiting rooms 
to provide more privacy, and providing a sliding fee scale and health education and counseling services, might also facilitate access by young people. In addition, improving system efficiency and increasing staffing in these locations may decrease waiting times and negative attitudes that may be associated with them. Finally, novel service features that would need to be provided to meet the described "ideal" include locations close to neighborhoods and routine urine-based specimen collection for males. Providing highly sensitive urine-based screening, utilizing DNA amplification techniques, may also improve disease detection, especially asymptomatic disease. [28] More research may be indicated to test if the modification or addition of these features increase screening rates.

Other authors have suggested offering screening and testing services outside of traditional medical facilities. [29] However, the mixed feelings our participants reported about seeking services in community settings highlights the delicate balance that may need to be struck between offering services in a setting familiar enough to make it convenient, but private enough to ensure confidentiality.

Finally, even with the provision of ideal STD services, adolescents may not assess their risk of disease well [30-32] and therefore may still not seek screening for asymptomatic disease. Increasing youth's ability to accurately perceive their risk of and the potential severity of STDs may prompt more youth to seek STD screenings and services. [31-33]

There were several limitations to our study. Using five moderators, who were trained individually, resulted in inconsistencies among topics addressed and the depth to which they were explored. Therefore, we could make only general estimates of the extent to which an opinion was shared by participants across groups. The validity of the results is limited by the lack of multiple coders and the fact that the groups did not give feedback on the results. We did not collect quantitative information from participants regarding socioeconomic status and personal experience with STDs. Therefore, we could not link these characteristics with opinions expressed in the focus groups. The representativeness and generalizability of the results to other youth in Wake County or in other geographic areas are further limited by the convenience sampling methods, small sample size, and the inherent limitations of focus group related group dynamics. However, these results were intended to generate questions or hypotheses that could be explored in larger, more representative studies.

\section{Conclusions}

Focus group participants identified many barriers to STD care consistent with other studies, including lack of knowledge of STDs, cost, inconvenient services, shame, and urethral swabs as method of specimen collection. Participants suggested that these barriers may more effectively deter youth from seeking asymptomatic screening as compared to seeking testing for symptomatic disease or after a known exposure. Conversely, with the exception of some Latino males, our participants did not report interpersonal barriers identified by other studies, including perceived racism and judgmental or scolding behavior on the part of the health care providers. Further research may be warranted to evaluate using certain mass media methods, including television and radio, to disseminate information about the importance of STD screening and available services, improving convenience, efficiency, privacy, and welcoming atmosphere of existing services, and providing urine-based screening and new services closer to neighborhoods as strategies to increase STD screening rates for youth.

\section{Competing interests}

None declared.

\section{Authors' contributions}

All of the authors have read and contributed greatly to the drafting and editing of the manuscript.

Other specific contributions include: ET led the design of this work and the writing of the manuscript; VS contributed greatly to the design of the work, especially the development of the focus group guide; CF contributed to the design of the work, including development of the focus group guide and recruitment of the focus group moderators and participants; and MS, PL, KF, KI, and WM all contributed greatly to the conception of the project.

\section{Acknowledgements}

This work was a component of Project 813, a collaborative agreement between the Centers for Disease Control and Prevention and the North Carolina Department of Health and Human Services. Dr. Tilson received additional support from the Duke Cancer Prevention, Detection, and Control Research Program. Dr. Miller was supported by the Clinical Associate Physician Program of the General Clinical Research Center (RR00046), Division of Research Resources, National Institutes of Health. The authors wish to acknowledge the efforts of Alan Muriera, Tangela Keaton, Gabriel Lamazares, and Wendy Cardenas who aided greatly in the recruitment and conducting of the focus group discussions. In addition, the authors would like to acknowledge Claire Viadro for her help in the data analysis. Finally, the authors would like to acknowledge Maysoun Freij, Rheta Barnes, and Mary Kamb for their contributions to this project.

\section{References}

I. Godin G, Fortin C, Mahnes G: University students' intention to seek medical care promptly if symptoms of sexually transmitted diseases were suspected. Sex Transm Dis 1993, 20:100-104. 
2. Institute of Medicine: The Hidden Epidemic: Confronting Sexually Transmitted Diseases Edited by: Eng TR, Butler WT. National Academy Press; 1997.

3. Crosby R, Leichliter J, Brackbill R: Longitudinal prediction of sexually transmitted diseases among adolescents: Results for a national survey. American Journal of Preventive Medicine 2000, 18:312-317.

4. Hitchcock P: Adolescents and sexually transmitted diseases: An important strategy for reducing the risk of HIV transmission. AIDS Patient Care STDS 1996, 10:79-85.

5. Laumann E, Youm Y: Racial/ethnic group differences in the prevalence of sexually transmitted diseases in the United States: A network explanation. Sex Transm Dis 1999, 26:250-26I.

6. Moses S, Manji F, Bradley J, et al.: Impact of user fees on attendance at a referral center for sexually transmitted disease in Kenya. Lancet 1992, 340:463-466.

7. Benjarattanaporn P, Lindan C, Mills S, et al.: Men with sexually transmitted diseases in Bangkok: Where do they go for treatment and why? AIDS 1997, I I (suppl):S87-95.

8. Fortenberry J: Health care seeking behaviors related to sexually transmitted diseases among adolescents. American Journal of Public Health 1997, 87:417-420.

9. Harrison A, Wilkinson D, Lurie M, et al.: Improving quality of sexually transmitted disease case management in rural South Africa. AIDS 1998, 12:2329-2335.

10. Hope V, MacArthur C: Acceptability of clinics for sexually transmitted diseases among users of the "gay scene" in the West Midlands. Genitourinary Medicine 1997, 73:299-302.

II. Leenaars P, Rombuts R, Kok G: Seeking medical care for a sexually transmitted disease: Determinants of delay-behavior. Psychologic Health 1993, 8: 17-32

12. Irwin D, Thomas J, Spitters C, et al.: Self-treatment patterns among clients attending sexually transmitted disease clinics and the effect of self-treatment on STD symptom duration. The Study Group. Sex Transm Dis 1997, 24:372-377.

13. Lieu T, Newacheck P, McManus M: Race ethnicity and access to ambulatory care among US adolescents. American Journal of Public Health 1993, 83:960-965.

14. Judson F: Gonorrhea. Medical Clinics of North America 1990, 74:1353-1376.

15. Hook E, Richey C, Leone P, et al:: Delayed presentation to clinics for sexually transmitted diseases by symptomatic patients. Sex Transm Dis 1997, 24:443-448.

16. O'Donnell L, San Doval A, Vornfett R, et al:: STD prevention and the challenge of gender and cultural diversity: Knowledge, attitudes, and risk behaviors among Black and Hispanic inner city STD clinic patients. Sexually Transmitted Disease 1994, 21:137-| 48 .

17. Ramirez-Valles J, Zimmerman M, Newcomb M: Sexual risk behavior among youth: Modeling the influence of prosocial activities and socioeconomic factors. Journal of Health and Social Behavior 1998, 39:237-253.

18. United States Census Bureau: United States Department of Commerce. United States 2000.

19. Division of STD Prevention: Sexually Transmitted Disease Surveillance, 1999. Atlanta: Department of Health and Human Services, Atlanta: Centers for Disease Control and Prevention 2000.

20. Epidemiology and Special Studies Unit, Prevention, \& and Care Branch: North Carolina STD Surveillance Report, 2000. North Carolina Department of Health and Human Services, Division of Public Health 2000 .

21. Schuster J, Thomas J, Eng E: Bridging the culture gap in sexually transmitted disease care. North Carolina Medical Journal 1995 56:256-269

22. American Academy of Pediatrics Committee on Public Education: Sexuality, contraception, and the media. Pediatrics 200I, 107:191-194.

23. Advocates for Youth: Contraceptive product advertising: Broadcast media, teenagers, and sexuality. Washington, $D C$ Center for Population Options 1984.

24. Strasburger VC: Getting teenagers to say no to sex, drugs, and violence in the new millennium. Medical Clinics of North America 2000, 84:787-810.

25. Kirby D: Sexuality and sex education at home and school. Adolescent Medicine 1999, 10:195-209.
26. Miller D, Levin $M$, Whitaker $D$, et al.: Patterns of condom use among adolescents: The impact of mother-adolescent communication. American Journal of Public Health 1998 , 88: I542-I544.

27. Whitaker D, Miller K, May D, et al.: Teenage partners' communication about sexual risk and condom use: The importance of parent-teenager discussions. Family Planning Perspectives 1999 , 31:117-121.

28. Braverman P: Sexually transmitted diseases in adolescents. Medical Clinic of North America 2000, 84:860-899.

29. Hitchcock P: Screening and treatment of sexually transmitted diseases: An important strategy for reducing the risk of HIV transmission. AIDS Pat Care STDs 1996.

30. Liljegren A, Lindgren G, Brandberg $Y$, Rotstein S, Nilsson B, Hatschek $T$, Jaramillo $E$, Lindblom A: Individuals with an increased risk of colorectal cancer: perceived benefits and psychological aspects of surveillance by means of regular colonoscopies. J Clin Oncol 2004, 22:1736-42.

31. Robb KA, Miles A, Wardle J: Subjective and objective risk of colorectal cancer (UK). Cancer Causes Control 2004, I 5:2 I-5.

32. Holloway RM, Wilkinson C, Peters TJ, Russell I, Cohen D, Hale J, Rogers $\mathrm{C}$, Lewis $\mathrm{H}$ : Cluster-randomised trial of risk communication to enhance informed uptake of cervical screening. $\mathrm{Br} J$ Gen Pract 2003, 53:620-5.

33. Lipkus IM, Green LG, Marcus A: Manipulating perceptions of colorectal cancer threat: implications for screening intentions and behaviors. J Health Commun 2003, 8:213-28.

\section{Pre-publication history}

The pre-publication history for this paper can be accessed here:

\section{http://www.biomedcentral.com/1471-2458/4/21/prepub}

Publish with Biomed Central and every scientist can read your work free of charge

"BioMed Central will be the most significant development for disseminating the results of biomedical research in our lifetime. "

Sir Paul Nurse, Cancer Research UK

Your research papers will be:

- available free of charge to the entire biomedical community

- peer reviewed and published immediately upon acceptance

- cited in PubMed and archived on PubMed Central

- yours - you keep the copyright 